\title{
Las causas de la crisis financiera en México
}

\author{
Henio Millán Valenzuela \\ El Colegio Mexiquense
}

\section{Introducción}

En diciembre de 1994, cuando la opinión pública se inclinaba a pensar que las crisis económicas se habían desterrado para siempre del escenario nacional, el anuncio de una nueva devaluación del peso cimbró los pilares en los que se había fincado un optimismo desbordado, que había tardado seis años en construirse, y unos cuantos días, en desmoronarse.

Esta nueva edición agregaba, sin embargo, tres novedades a los tradicionales tropiezos que desde los setenta venía registrando la economía mexicana: se producía tras una profunda reforma estructural en pro de una mayor liberación de los mercados y después de que se habían logrado avances sustanciales en el combate en la inflación y en las disciplinas fiscal y monetarias; demandaba ajustes más severos, pero menos prolongados, en el nivel de actividad económica y el bienestar, y, por último, activó mecanismos que, al arrastrar a las instituciones financieras, pusieron en riesgo el sistema de pagos del país.

Este último elemento impulsó a las autoridades a emprender una estrategia de rescate bancario, que acarreará un costo que se antoja demasiado oneroso para las generaciones actuales y, probablemente, para las venideras. Por ello, la revisión de las causas que propiciaron la crisis financiera se vuelve obligada en dos sentidos: para evitar incurrir en los mismos errores y para fincar, política y moralmente, la responsabilidad de quienes condujeron los destinos del país durante el periodo en el que esas causas se incubaron. Pero el examen aporta una ventaja adicional: señalar los puntos que privilegiadamente debe atender la re-

Economía, Sociedad y Territorio, vol. II, núm. 5, 1999, 25-66. 
forma al sistema financiero, si se quiere que éste se vuelva menos vulnerable a los vaivenes del entorno nacional e internacional.

Este trabajo tiene, precisamente, ese objetivo: demostrar que el colapso del sistema financiero fue, en muy buena medida, evitable, de haber mediado una política económica más prudente y acciones más responsables en materia de supervisión y regulación bancaria. A su gestación contribuyeron factores macroeconómicos, ligados a los excesos de la política que desembocó en la crisis económica iniciada en diciembre de 1994, y otros de índole microeconómica que se tradujeron en un auge crediticio que fue desligándose cada vez más de la dinámica real de la economía nacional. En ambos grupos, se entreveran ingredientes sorpresivos, pero también los previsibles. Se intenta distinguirlos, pero también enfatizar aquellos que, a pesar de emitir anticipadamente señales de alarma, no fueron atendidos con la oportunidad suficiente, o que fueron relegados en función de otros intereses.

El trabajo consta de tres partes. En la primera se exponen las causas macroeconómicas de la crisis financiera, a la luz de los acontecimientos que condujeron a la devaluación de 1994 y a la recesión de los siguientes años. En la segunda se analizan los factores microeconómicos que propiciaron que las instituciones financieras, especialmente los bancos, se volvieran extremadamente vulnerables a los cambios del entorno económico. En la última parte se examinan los efectos desencadenantes de la política postdevaluatoria sobre las crisis bancarias.

\section{A. Las causas macroeconómicas}

\section{La inflación y la estrategia exportadora}

\subsection{La estrategia exportadora: una necesidad ineludible y una estrategia postergada por los gobiernos populistas}

Los colapsos económico-financieros de 1976 y de 1988 demostraron de forma palmaria que el modelo de desarrollo iniciado en los años cuarenta había alcanzado límites que sólo podían ser franqueados a costa de propiciar crisis más frecuentes y más severas. El trasfondo de estos episodios era la imposibilidad de continuar impulsando el crecimiento por medio de las fuerzas que afectan directamente el mercado interno. Con el agotamiento del proceso de sustitución, que se evidenció a principios de los años 
setenta, la economía mexicana había agotado los motores endógenos de crecimiento, como ya lo atestiguaba la disminución del ritmo de expansión de la inversión privada en los últimos años del llamado desarrollo estabilizador. Ante esta coyuntura, México:

[.... tenía en la década de los setenta dos alternativas a seguir: la primera, orientar el rumbo del programa de desarrollo hacia una economía de exportación, como lo hizo Corea en 1965; la segunda, continuar con la ruta trazada, reemplazando la inversión privada, con mayor gasto del gobierno. México optó por esta última opción (Aspe, 1993:22).

La consecuencia más gravosa de haber escogido la alternativa de continuar impulsando el mercado interno por una vía exógena, como el gasto público, consistió en que se imprimió a la economía un comportamiento caracterizado por "arranque y freno", en el que los periodos de auge y los de depresión se sucedían alternadamente (Casar, 1989; y Tello, 1979). Para comprender mejor esta forma de desempeño, es conveniente recurrir a las siguientes dos expresiones: ${ }^{1}$

$$
Y=\frac{G+X}{p(1-c)+\left[{ }^{a} /(1-a)\right]}
$$

[2]

$$
\frac{X-M}{Y}=\frac{T-G}{Y}+\frac{S-I}{Y}
$$

(Donde las variables son las siguientes: $Y$, ingreso o producto interno bruto; $X$, exportaciones; $p$, la participación de las ganancias en el ingreso nacional; $c$, la propensión media a consumir, que se considera cambia poco en el corto plazo; $a$, el coeficiente de sustitución de importaciones; $M$, las importaciones; $T$, los ingresos públicos; $G$, el gasto público; $S$, el ahorro privado; e $I$, la inversión privada).

\footnotetext{
${ }^{1}$ La derivación de estas expresiones puede encontrarse en Millán, 1997.
} 
$\mathrm{Al}$ agotarse el proceso de sustitución de importaciones, ${ }^{2}$ el impulso al crecimiento del ingreso nacional y del producto depende del gasto público y de la exportación, dados el nivel de distribución del ingreso y la propensión a consumir. Sin embargo, como lo muestra la segunda expresión, el aumento del gasto público afecta negativamente al balance público $(T-G)^{3}$ y, por este conducto, al saldo en la cuenta corriente de balanza de pagos. Al acumularse déficit externos mayores y disminuir las reservas nacionales, las autoridades financieras se ven obligadas a elevar el tipo de cambio y a activar políticas fiscales y monetarias restrictivas, que acaban por frenar el crecimiento y por hundir el nivel de actividad en una clara depresión. El efecto de tales políticas se hace sentir en un alivio en las cuentas externas, para reanudar un nuevo ciclo de expansión impulsado por el gasto público que, inevitablemente, desembocará en una nueva crisis de la balanza de pagos y en una nueva devaluación del peso.

La continuación artificial de un modelo agotado, emprendida por las administraciones de Luis Echeverría y José López Portillo, no sólo inauguró la crisis de la economía mexicana, sino que además le dio un sentido estructural: la incapacidad para crecer sin provocar desequilibrios que, al final, acababan por frenar el crecimiento mediante depresiones cada vez más severas y más prolongadas. La política económica de largo plazo iniciada por el gobierno del presidente Miguel de la Madrid y profundizada por su sucesor, se abocó a virar el rumbo hacia un modelo de desarrollo fincado en la exportación de manufacturas, de conformidad con las restricciones que las condiciones internas y externas imponían a la gama de opciones para el desarrollo. Sin embargo, esta transición fue operada en una forma que terminó desembocando en una nueva crisis de balanza de pagos, en una nueva devaluación abrupta del peso y en una caída del producto -total y per cápita- inédita en la historia moderna de la economía nacional.

Los expedientes más importantes para reorientar el aparato productivo hacia los mercados externos fueron la apertura

${ }^{2}$ El avance en la sustitución de importaciones implica un descenso continuo de la participación de las importaciones en la oferta agregada, que es lo que mide el coeficiente "a".

${ }^{3}$ Un aumento en el gasto público incrementa también el nivel de recaudación, por sus efectos en el ingreso; sin embargo, las variaciones en la recaudación son siempre inferiores a los aumentos en el gasto público, cuando la economía no se encuentra en el nivel de pleno empleo. Una demostración de esta proposición puede encontrarse en Dornbush y Fisher, 1985, p. 91. 
comercial a la competencia foránea y la reforma económica del Estado. El desmantelamiento del sistema de protección pretendía, por el lado de la oferta, disminuir el sesgo antiexportador y alterar la rentabilidad relativa a favor de la ventas externas; ${ }^{4} \mathrm{y}$ por el lado de la demanda, acicatear la competitividad de las empresas nacionales. Por la reforma económica del Estado apuntaba hacia una mayor liberación del mercado, de tal forma que el sistema de precios relativos pudiera operar como un eficiente emisor de señales y como el protagonista del proceso de asignación de los recursos. En esta dirección, se instrumentó un redimensionamiento del aparato estatal, que abarcó tanto al sector gubernamental como a las empresas públicas, muchas de las cuales fueron privatizadas; la economía se encarriló hacia esquemas de operación menos regulados, mientras otros elementos que afectaban al sistema de precios, como los subsidios y las tarifas de los bienes y servicios suministrados por el Gobierno, fueron racionalizados. Estos cambios, si bien incompletos, fueron trascendentes para impulsar la competitividad de la economía nacional y para cambiar - parcial, pero significativamente- el destino de la producción hacia el exterior.

\subsection{La estrategia exportadora y el combate a la inflación}

Las autoridades encargadas de hacer de la industria una actividad exportadora encararon el problema de la inflación. Su combate era vital para el éxito de la estrategia, pues una inflación alta e incontrolable podría dar al traste con los avances de las mejoras en la productividad laboral y en la competitividad, que operaban como una de las premisas claves del nuevo desempeño exportador (Cuadro 1). Por tal razón, la batalla antiinflacionaria se convirtió en el eje de la política económica de corto plazo, de 1982 a 1994, pero sobre todo bajo el gobierno del presidente Salinas de Gortari (Aspe, 1993; y Ramírez de la O, 1996).

Tras el fracaso de las políticas de estabilización orientadas a afectar la demanda agregada, ${ }^{5}$ el gobierno mexicano anunció en diciembre de 1987 un programa heterodoxo, que combinaba

\footnotetext{
${ }^{4}$ La protección efectiva mide la diferencia porcentual entre el valor agregado que se obtiene al vender al mercado interno y el correspondiente a la venta al mercado internacional; es, en este sentido, un indicador del sesgo antiexportador y de la rentabilidad mercado externo con relación al interno (Chacholiades, 1986:217).

${ }^{5}$ Una explicación convincente de por qué fracasan las políticas ortodoxas en países con estructuras productivas y mercados como el de México, se puede consultar Aspe, 1993.
} 
una política de ingresos con disciplinas en el orden fiscal monetario. El objetivo explícito era reducir la inflación, mediante la eliminación de su componente inercial, sin afectar el crecimiento económico.

El diagnóstico del fenómeno inflacionario se deslizaba hacia otro tipo de cuestionamientos: la pregunta relevante ya no era el origen de la inflación -que la primera etapa estabilizadora había identificado con un exceso de demanda agregada-, sino las razones que conducían a que ésta resistiera, a pesar de que los principales desequilibrios fiscales y monetarios habían sido corregidos. El tema había sido examinado por otros analistas, y sus recomendaciones, adoptadas por otras naciones, aunque con éxitos variados. La respuesta provino de dos fuentes: la inercia inflacionaria y el conflicto distributivo, implícito en la distorsión de los precios relativos.

Cuando existe un ambiente de alta inflación, los agentes económicos tratan de ajustar sus precios $-\mathrm{y}$ por tanto sus ingresos- indexándolos a la inflación futura; pero en la medida en que este indicador es desconocido, acaban por utilizar la tasa de crecimiento de los precios pasada-sobre todo la de periodos recientes- como un instrumento que pronostica un mínimo de inflación esperada. De esta forma, la inflación pasada se transmite al ajuste que los agentes realizan en sus precios. El fenómeno adquiere un carácter inercial, en el que las expectativas juegan un papel crucial.

Por otro lado, la inflación no sólo implica un lanzamiento al alza del nivel de precios, como generalmente se cree, sino también una alteración en los precios relativos: el crecimiento desigual de las cotizaciones de los bienes y servicios propicia una desalineación de los precios relativos que acaba por propiciar una redistribución de los ingresos reales más amplia que la clásica entre sectores de ingresos fijos e ingresos variables. Con el afán de defender sus ingresos reales, los agentes económicos se ven imposibilitados de no incrementar sus precios si sus expectativas les dicen que los demás no detendrán sus ajustes continuos; si, adicionalmente, esperan que estos movimientos serán proporcionalmente mayores a los previamente realizados, la tasa de inflación tenderá a elevarse por encima de la registrada en el pasado. De esta forma, la inflación tiende a reproducirse y a revestirse de un carácter inercial, independientemente de que hayan desaparecido los desequilibrios de naturaleza fiscal o monetaria. 
Existen dos formas de combatir la inercia inflacionaria: la primera apuesta al congelamiento de precios, salarios y del tipo de cambio nominal; esto es un choque heterodoxo. La segunda se inclina por configurar una estrategia concertada de aumentos proporcionales en todos los precios: se trata de los pactos. Esta fue la opción que adoptaron las autoridades mexicanas, a partir de los últimos días de 1987, cuando la sociedad civil conoció su primera edición: el Pacto de Solidaridad Económica (PSE).

En una primera etapa, que terminó en marzo de 1988, la estrategia se centró en la realineación de los precios relativos, por medio de ajustes en los precios y tarifas del sector público, la elevación del tipo de cambio, las tasas de interés y los salarios y, sobre todo, por medio de una virtual liberación de los precios, que incluía la conservación, en términos reales, de los correspondientes a los de garantía para el sector agrícola. Estas medidas fueron acompañadas de disminuciones en el gasto público y de una profundización de la apertura comercial, con la finalidad de que una mayor competencia externa construyera techos a los precios internos. A partir de entonces, la estrategia se perfiló hacia dos frentes: cambiar las expectativas inflacionarias y eliminar el conflicto distributivo implícito en las distorsiones de los precios relativos.

En el primer frente, se trataba de que los agentes sustituyeran la inflación pasada por la futura o esperada, como referente de indexación. El centro de esta línea de acción consistió en anuncios anticipados de las modificaciones que sufrirían los precios y tarifas del sector público, el tipo de cambio y los salarios. La lógica que la animaba era la siguiente: en países como México, donde no existe un mercado de futuros desarrollados, las expectativas de inflación están fuertemente influidas por la trayectoria de ciertos "precios claves", como son los salarios mínimos, el tipo de cambio y los precios de bienes de uso generalizado, generalmente suministrados por el Estado. En este sentido, los anuncios anticipados de las modificaciones que habrían de operar en esos rubros procuraban cimentar en los agentes económicos un conjunto de nuevos referentes para su proceso de indexación de los precios. En la medida en que los anuncios anticiparan efectivamente los movimientos efectivos en esos referentes, la credibilidad del programa se afianzaría y las autoridades contarían con instrumentos eficaces para ajustar las expectativas de inflación a la baja. 
Los "precios claves" -sobre todo el tipo de cambio- operaron como anclas del programa de estabilización. Por esta razón permanecieron invariables hasta prácticamente la segunda edición del pacto: ${ }^{6}$ el Pacto para la Estabilidad y el Crecimiento Económico (PECE), emitido al inicio de la administración del presidente Salinas. Sin embargo, esta nueva visión no alteró la lógica que animó a la primera emisión: el tipo de cambio siguió bajo un régimen de tipo de cambio fijo, sin devaluaciones abruptas, pero ahora bajo la modalidad de deslizamientos diarios, y anunciados anticipadamente, de la paridad; ${ }^{7}$ y los aumentos de los salarios y de las tarifas y precios de los salarios mínimos fueron ajustados a la inflación esperada. En la medida en que ésta siempre resultó inferior a la registrada, las remuneraciones laborales se deterioraron en términos reales.

En el frente de la realineación de precios, la política contra la inflación operó mediante esquemas de concertación entre las cúpulas empresariales, sindicales y de las organizaciones campesinas. El Gobierno echó mano de los mecanismos corporativos, en franca descomposición en el terreno de la representatividad, pero todavía eficaces en el ejercicio del autoritarismo mexicano. Por medio de ellos el poder del Estado se impuso para detener las demandas salariales y las solicitudes de mayores precios de garantía de los productores agropecuarios; pero también para controlar una gama de bienes seleccionados, que inicialmente permanecieron constantes, pero que después fueron modificados de forma concertada.

El mecanismo de concertación se extendió a otros productos cuando el acuerdo apuntó hacia la concesión generalizada de descuentos entre proveedores y empresas que atienden la demanda final, y entre éstas y los consumidores. Para convencer a empresarios renuentes, el Estado contaba con un instrumento muy eficaz, joya del nuevo autoritarismo: el uso indiscriminado de la protección arancelaria. En aquellos sectores en los que los aumentos de precios no obedecían a los que previamente se habían concertado, el Gobierno amenazaba con reducciones de arance-

${ }^{6}$ La única modificación se registró en los salarios mínimos, con un pequeño aumento de 3 por ciento.

${ }^{7}$ El régimen de tipo de cambio fijo se define por la paridad, y los cambios que ésta experimenta están determinados exógenamente, mientras el nivel de reservas internacionales opera como una variable endógena. En la medida en que el deslizamiento es fijado por la autoridad, el deslizamiento opera como un tipo de cambio fijo. Lo mismo sucede con el sistema de bandas: no es el mercado el que determina cabalmente la paridad. 
les, incluso hasta eliminarlos, a efecto de que operara la "ley de un solo precio".

\section{La estrategia contra la inflación, el tipo de cambio y la balanza de pagos}

La estrategia de los pactos fue exitosa en función del objetivo de disminuir la inflación, sin afectar negativamente el crecimiento. La inflación descendió de 160 por ciento en 1987, a 7 por ciento en 1994; y durante ese periodo, el Producto Interno Bruto (РІв) mostró tasas positivas, aunque relativamente bajas, de crecimiento (Cuadro 2).

Sin embargo, el desempeño económico repitió la experiencia traumática de la expansión explosiva de la balanza de pagos: el déficit de la cuenta corriente comenzó a crecer a medida que la inflación cedía, hasta llegar a alcanzar proporciones del producto similares a las que precedieron a la crisis de 1982, pero con tasas de crecimiento sustancialmente inferiores a las que registró el auge petrolero. Tal comportamiento de la balanza de pagos fue, en ambos casos, el antecedente que condujo a la crisis; sin embargo, la de los años ochenta fue el resultado del un periodo de auge económico, tal y como fue descrito en el mecanismo de "arranque y freno"; en cambio, la de los noventa se produjo en el contexto de un crecimiento inferior al necesario para evitar el aumento del desempleo.

¿Qué le sucedió a la economía para que el déficit en la cuenta corriente alcanzara niveles tan peligrosos, en un escenario de finanzas públicas equilibradas, inflación descendente y bajo crecimiento? La respuesta se encuentra en el abuso del tipo de cambio y de la política comercial como instrumentos de combate a la inflación.

Como se ha apuntado, el tipo de cambio nominal sirvió como "ancla" del programa de estabilización. Aunque sufrió modificaciones en el curso de este programa (de estar completamente fijo, al deslizamiento, y de éste a una banda creciente), ${ }^{8}$ sus

\footnotetext{
${ }^{8}$ El tipo de cambio permaneció sin modificaciones hasta 1989; a partir de ese año, comenzó el deslizamiento de la paridad en relación con el dólar: un peso diario, durante ese año; en 1990 y 1991, se redujo a 80 y 40 centavos, respectivamente. A partir de noviembre de ese último año, se estableció un tipo de cambio que fluctuaba en una banda de flotación, cuyo tope máximo aumentaba .0002 nuevos pesos. Para octubre de 1992, este incremento del techo de la banda pasó a 0.0004 nuevos pesos, que permaneció hasta el 20 de diciembre de 1994.
} 
movimientos redundaron en una apreciación real del tipo de cambio, es decir, en una sobrevaluación creciente del peso, en la medida en que fueron inferiores al diferencial de inflaciones entre México y los Estados Unidos (Cuadro 3).

La apertura comercial, por su parte, había sido originalmente diseñada como un instrumento de política de largo plazo, dirigida a propiciar el cambio estructural necesario para hacer de la economía una actividad exportadora; no obstante, la estrategia de los pactos la transformó en una política de corto plazo, enfocada al combate a la inflación. Con la finalidad de que los precios internacionales operaran como un tope de los domésticos, el PSE modificó los términos de desgravación programados en el protocolo de adhesión de México al Acuerdo General sobre Aranceles Aduaneros y Comercio (GATT, por sus siglas en inglés). El arancel máximo descendió de 40 a 20 por ciento, mientras la gama de tasas por este rubro se redujo a cinco; el arancel promedio, que en 1985 era de 22.6 por ciento, para 1988 había alcanzado un porcentaje de 13.1; y la cobertura de los permisos previos pasó de 21.2 a 9.1, de 1988 a 1991 (Aspe, 1993:46).

La combinación de una mayor apertura con un tipo de cambio que crecientemente sobrevaluaba la moneda nacional, terminó por reflejarse en un considerable déficit de la cuenta corriente de la balanza de pagos, al mismo tiempo que reducía la tasa máxima de crecimiento económico compatible con la restricción externa. La responsabilidad de ambas variables sobre el crecimiento de las importaciones, y por esta vía, sobre la balanza de pagos, puede apreciarse en la siguiente estimación lineal:

$$
M=\alpha+\beta L N P I B+y E R
$$

Donde $M$ representa la importación total; PIB, el producto interno bruto; $E R$, el tipo de cambio real; mientras los parámetros son la constante de la ecuación y la elasticidad de las importaciones en relación con el producto y el tipo de cambio.

\begin{tabular}{|c|c|c|c|c|c|}
\hline Periodo & $\alpha$ & $\beta$ & $y$ & $\mathrm{R}^{2}$ & $\mathrm{~F}$ \\
\hline $1975-1985$ & $\begin{array}{c}-12.1 \\
(-3.4)\end{array}$ & $\begin{array}{c}2.4 \\
(6.6)\end{array}$ & N.S. & .84 & 22.1 \\
\hline $1985-1995$ & -33.6 & 4.1 & 1.1 & .80 & 16.7 \\
& $(-4.72)$ & $(5.53)$ & $(3.7)$ & & \\
\hline
\end{tabular}

Los números entre paréntesis son las pruebas t; N.S., estadísticamente no significativo. 
Los resultados de la estimación lineal muestran que: a) el tipo de cambio, y por ello los precios relativos, no jugaban un papel significativo en la determinación del nivel de importaciones, mientras la economía permaneció cerrada; es con la apertura que empieza a constituirse en uno de los factores explicativos de su comportamiento; $b$ ) con la apertura comercial, iniciada en 1985 y profundizada con la estrategia de los pactos, la elasticidad de las importaciones ${ }^{9}$ se eleva sustancialmente, lo que da cuenta de un desplazamiento de la producción doméstica por productos de origen doméstico, y por esto, de una tasa de crecimiento económico inferior compatible con una proporción dada del déficit comercial; y c) la sobrevaluación del peso es uno de los determinantes del saldo negativo en la cuenta corriente de la balanza de pagos, en la medida en que es el crecimiento de las importaciones el principal detonador de la expansión que registró ese rubro durante el tiempo en que estuvo vigente el Pacto.

Las modificaciones que las políticas comercial y cambiaria introdujeron en el funcionamiento son dos expedientes ineludibles en la explicación de por qué el crecimiento fue lento; la inflación, descendente, y el déficit externo -como proporción del producto-, similar al que precedió a la crisis de 1982. Ambas políticas condujeron a una mayor penetración de bienes foráneos en la demanda interna y en la oferta agregada, que se tradujo en un proceso inverso al de la sustitución de importaciones (Cuadro 4). De esta forma, instauraron una fuerza negativa sobre el crecimiento, que contrarrestó los efectos positivos que sobre esta dinámica tuvo el indiscutible avance exportador.

\section{El financiamiento del déficit corriente y el riesgo de una nueva crisis}

A pesar de que el déficit en la cuenta corriente de la balanza de pagos crecía, el nivel de reservas internacionales continuaba aumentando desde 1988. Este hecho parecía avalar la confianza de las autoridades y de los inversionistas extranjeros en el peso:

${ }^{9}$ La elasticidad es un indicador que muestra el cambio porcentual en una variable, provocada por un cambio, también porcentual, en otra variable. La estimación muestra que, para el periodo 1985-1995, por cada punto porcentual de aumento en el PIB, las importaciones crecían 4.1 por ciento, mientras que en el lapso 1975-1985, lo hacían en 2.1 por ciento. 
En relación con la balanza comercial y la cuenta corriente, observamos que dichas variables se han desplazado de superávit antes del Pacto a un considerable déficit en la actualidad. Sin embargo, en contraste con lo ocurrido en los años anteriores a la crisis, estas cifras no son reflejo de una economía sobrecalentada, impulsada por el gasto del gobierno y por el sobreendeudamiento externo, sino de una acelerada expansión de la inversión -financiada en forma directa con la repatriación de capitales, los flujos de inversión de compañías extranjeras y préstamos voluntarios del sector privado. Consecuentemente, a pesar de la magnitud del déficit, se acumularon reservas que en noviembre de 1991 fueron aproximadamente 16 mil millones de dólares, el nivel más alto alcanzado en México (Aspe, 1993:47).

La clave de este comportamiento se encontraba en la cuenta de capital de la balanza de pagos: como muestra el Cuadro 5, desde 1990 el superávit de este rubro comenzó a financiar sobradamente el saldo de las transacciones corrientes con el exterior; de esta forma, posibilitó la coexistencia de déficit corrientes explosivos con aumentos en las reservas internacionales.

El saldo positivo provenía de entradas masivas de capitales, en forma de inversión extranjera, tanto directa como en cartera. Sin embargo, como es visible en el mismo cuadro, con excepción del primer año del Pacto, la inversión productiva de origen foráneo fue siempre insuficiente para cubrir las cuentas corrientes. Por tal razón, su financiamiento empezó a depender crecientemente de los flujos de capital colocados en activos financieros, que pasaron a representar, abrumadoramente, el componente más importante de la inversión foránea total. El riesgo comenzó cuando esos recursos se fueron trasladando del mercado de capitales hacia el de dinero, especialmente hacia títulos gubernamentales, que ofrece perfiles de vencimiento mucho más cortos. Entonces, la estabilidad del tipo de cambio y de las condiciones macroeconómicas dependieron de la permanencia de esos capitales de índole especulativa. Las expectativas devaluatorias y la brecha entre las tasas de interés internacionales y las domésticas, resumidas en el "riesgo país", pasaron a constituir los alfileres de los que pendía la estabilidad de la economía nacional.

La entrada masiva de capitales, por otra parte, se sumó a la revitalización del tipo de cambio real que había propiciado la política cambiaria, en la medida en que una mayor oferta de divisas contribuía a mantener el tipo de cambio nominal, a pesar de la vigencia de las brechas entre la inflación doméstica y la internacional. Pero a su vez, la apreciación real del tipo de cambio contribuyó a la expansión del consumo y de la inversión, cuyo ritmo 
de crecimiento superó al del PIB. La consecuencia no pudo ser otra que la disminución del ahorro interno y una creciente dependencia del externo, encarnado en ese flujo intenso de capitales externos que ingresaron al país (Cuadro 6).

La entrada de capitales y un peso sobrevaluado, al operar en un contexto de mayor apertura externa, liberaron la demanda "reprimida" de importaciones, precisamente porque el deterioro de las cuentas externas restó credibilidad sobre la permanencia de la política comercial. Con un déficit en cuenta corriente de tales proporciones, aunado a la insistencia de mantener el tipo de cambio, la única opción racional para numerosos agentes económicos era el regreso a los tiempos de la economía cerrada (Lustig, 1995:376-377).

Paro también los flujos de capitales posibilitaron el aumento del consumo y la inversión privados, mediante un crecimiento desmedido del crédito interno. La ausencia de una supervisión y de un marco regulatorio adecuado, como después se verá, dieron pie a que esos recursos se canalizaran a la compra de bienes de consumo duradero -especialmente los hipotecarios-, que serían la simiente de las carteras vencidas y de un perfil más riesgoso de los activos bancarios.

Al iniciar 1994, la economía mexicana ya mostraba todos los elementos que la harían extremadamente vulnerable a cambios adversos del entorno económico, político y social. Desafortunadamente, éstos no tardarían en presentarse.

\section{1994: turbulencias politicas y vulnerabilidad económica}

Ante la insistencia de las autoridades de mantener la política cambiaria, muchos analistas habían advertido desde 1992 la necesidad de imprimir mayor flexibilidad al tipo de cambio, para evitar que continuara su apreciación real. Una devaluación a tiempo habría impedido proseguir con el programa contra la inflación, pero hubiera evitado la crisis de 1994, por una sencilla razón: el nivel de reservas internacionales. Cuando la modificación abrupta del tipo de cambio obedece al agotamiento de estos activos, las políticas fiscales y monetarias tienen que emprender un camino más restrictivo, con la finalidad de restituir lo más pronto posible un nivel adecuado de reservas. Esto fue lo que sucedió en los años posteriores a 1982 y en 1995 . Es este carácter restrictivo el factor directo que conduce a la declinación del nivel de actividad; además, sólo cuando ha descendido el nivel de reservas, la 
devaluación despliega sus efectos contraccionistas y el deterioro del salario real opera como la principal variable de ajuste.

En cambio, cuando la elevación del tipo de cambio nominal se efectúa en un contexto en el que el nivel de reservas es aceptable, las expectativas apuntan hacia una pronta estabilización de la paridad, mejora la balanza de pagos y el producto puede expandirse, porque la política económica no se ve obligada a revestirse de un carácter restrictivo. La devaluación de diciembre de 1987, cuando se contaba con un nivel de reservas de 13 mil millones de dólares, es una prueba de ello.

El abuso en la utilización del tipo de cambio como arma contra la inflación corrió por dos derroteros. El primero consistió en la extensión de la política cambiaria más allá de los límites que el propio objetivo del Pacto le había impuesto. Ésta había sido diseñada para eliminar el componente inercial de la inflación; para 1992, cuando la tasa fue de 11.9 por ciento, ese objetivo ya se había cumplido. Por ello, la obstinación de conducirla hasta un dígito sólo pudo ser satisfecha en 1993, mediante el abandono del otro propósito del Pacto: no provocar recesión en el nivel de actividad. En ese año la economía permaneció prácticamente estancada, pues el PIB registró el crecimiento más bajo del periodo (0.7 por ciento), mientras el monto de deslizamiento del límite superior de la banda de flotación se redujo, aun cuando las expectativas se encaminaban hacia una ampliación de la misma. Haber recurrido a este expediente constituyó la prueba de que la política cambiaria ya poco podía incidir sobre el alza de precios, y que, por tanto, el sostenimiento del tipo de cambio dependía de la voluntad política y de que los capitales siguieran fluyendo hacia nuestro país. Aquélla era firme, pero insuficiente; éstos, persistentes, pero frágiles.

El segundo derrotero por el que transitó el abuso de la política cambiaria fue desaprovechar la oportunidad para modificar la paridad cuando se contaba con reservas internacionales suficientes. La última de ellas se presentó en marzo de 1994, tras el asesinato del candidato del Partido Revolucionario Institucional a la presidencia de la República. A diferencia de la aparición del movimiento armado en Chiapas, este suceso provocó una convulsión política que se tradujo en una disminución de las reservas de 9 mil millones de dólares en tan sólo un mes. A partir de entonces, y hasta noviembre, se estabilizaron en un nivel de 17 mil millones de dólares. 
La clave de este comportamiento fue la política monetaria que siguió el Gobierno como alternativa al cambio en la paridad: elevó las tasas de interés y recurrió a una mayor emisión de Tesobonos, títulos públicos indexados al dólar, que en la práctica significaba una dolarización de la deuda interna. La combinación de ambos expedientes había posibilitado responder al aumento en réditos del Tesoro norteamericano, que venían creciendo desde enero, y en el riesgo país, implícito en las turbulencias políticas que había desencadenado el asesinato de Luis Donaldo Colosio.

No obstante, la política de tasas de interés cesó en julio. A pesar de que los bonos del Tesoro norteamericano continuaron su tendencia alcista, las tasas domésticas de interés revirtieron su tendencia y emprendieron el camino cuesta abajo. Este giro fue uno de los errores más importantes que sirvieron de precedente directo a la devaluación de diciembre: prendida de los capitales extranjeros, la economía mexicana abría una de las principales grietas hacia la salida de recursos al exterior. Si se pretendía mantener la paridad, en un contexto en el que los activos financieros foráneos se volvían más atractivos, la política monetaria no podía darse el lujo de relajarse. Pero los efectos de tasas más altas de interés amenazaban el crecimiento en un año electoral.

La única arma disponible para defender la paridad, después de que fue abandonada la política monetaria restrictiva, fue la emisión de Tesobonos. Éstos pasaron de 3 mil millones de dólares en marzo, a 12600 en julio; para septiembre habían alcanzado una cifra de 19 200, y para diciembre, el incré́ble monto de 29 mil millones de dólares. Para estas fechas ya representaban 87 por ciento de la tenencia de deuda pública interna en manos extranjeras.

Pero la emisión de Tesobonos acarreaba dos problemas que terminaron por explotar en diciembre de 1994: representaban una señal de la falta de credibilidad en la política cambiaria y exhibían un perfil de vencimiento muy corto: del monto emitido, 17 mil millones vencían en 1997. Era tal la magnitud de la deuda de corto plazo contratada por medio de estos instrumentos, que los inversionistas empezaron a temer su incumplimiento. Así comenzaron las ventas de pánico (Lustig, 1995). Los agentes económicos saben leer los acontecimientos que pueden perjudicarles, por ello iniciaron la oleada especulativa que terminó con la devaluación. 


\section{B. Causas microeconómicas de la crisis financiera}

\section{El sistema bancario antes de 1982}

Hasta el inicio de la década de los setenta, el sistema bancario mexicano se había caracterizado por cumplir aceptablemente su principal función social: captar ahorro y transferirlo hacia las actividades productivas, en forma de inversión. La clave de tal desempeño había residido en la combinación de un entorno macroeconómico estable, sobre todo en los años sesenta, y de un sistema de banca especializada, que había cobrado carta de naturalidad a raíz de la expedición de la Ley de Instituciones y Organismos Auxiliares de Crédito en 1941.

Este precepto legal consignaba, además de la división del sistema en giros especializados en banca de depósito, sociedades financieras y en las de crédito hipotecario, la operación de "cajones" selectivos de créditos, mediante los cuales las autoridades tenían y ejercían la facultad de canalizar una parte de la captación hacia sectores previamente designados como prioritarios. Entre ellos se encontraba el Gobierno, que podía utilizarlos para financiar el déficit en las finanzas gubernamentales.

En la medida en que durante el desarrollo estabilizador el déficit público representó un porcentaje muy bajo del PIB, los requerimientos financieros del Gobierno no constituyeron una competencia por los recursos bancarios frente a las actividades productivas. Sin embargo, esta situación comenzó a cambiar desde el inicio de la administración del presidente Echeverría: cuando el gasto público inició su etapa de sustitución de la inversión privada como motor del crecimiento, los consecuentes déficit públicos demandaron recursos crecientes tanto del sistema bancario privado como del Banco de México, por medio de emisiones monetarias. Los resultados no tardaron en reflejarse en el funcionamiento de la banca: los cajones dedicados al Gobierno absorbieron una mayor proporción del crédito disponible, mientras afloraron presiones inflacionarias que al mezclarse con un control rígido de las tasas nominales de interés, acabaron por arrojar réditos reales más bajos -y en ocasiones negativos-, que redundaron en una menor captación bancaria, tanto en términos reales como en proporción del producto interno bruto. De esta forma, la banca incurrió en un periodo de desintermediación financiera que, con excepción del breve periodo del auge petrolero, caracterizaría a la década de los setenta. 
La respuesta de las autoridades ante la desintermediación fue doble: por una parte impulsaron la transición hacia la banca múltiple, y por la otra, abrieron la posibilidad de que los ahorradores mantuvieran cuentas denominadas en dólares, aun cuando los depósitos se hubieran efectuado en pesos (Quijano, 1982 ). El tránsito hacia la banca múltiple había tenido su primer antecedente en las modificaciones legales de 1970, que permitieron la integración de grupos bancarios por varias instituciones de créditos especializadas, pero conservando la prestación de servicios por departamentos independientes y especializados. En 1974 la Ley Bancaria reconocería el derecho de las instituciones para captar y suministrar servicios crediticios en forma integral bajo la figura de la banca múltiple. Este proceso culminaría en 1978, con nuevas disposiciones jurídicas que facilitarían las fusiones bancarias.

De esta forma, el sistema bancario había dado uno de los pasos decisivos para revertir las tendencias en la disminución de la captación y para emprender el camino hacia la revolución tecnológica que tendría lugar en la siguiente década; pero este proceso sería interrumpido por la expropiación decretada por el presidente López Portillo el primer día de septiembre de 1982.

\section{Las consecuencias de la expropiación bancaria}

En manos del Estado, la banca se convirtió en la tesorería que permitió financiar un déficit público que en 1982 llegó a ser el equivalente a 18 por ciento del PIB. Ante la escasez de recursos en los mercados internacionales de capital, y enfrascado en una política monetaria restrictiva que pretendía abatir la inflación por vías tradicionales, el gobierno del presidente de la Madrid fincó el financiamiento del enorme déficit público en aumentos nunca antes vistos del encaje legal, lo que terminó por reducir la disponibilidad de crédito para el resto de las actividades productivas.

Estos hechos determinaron el desarrollo de un mercado de crédito paralelo, en el cual el sector privado encontró respuesta a sus demandas de recursos. Los intermediarios no bancarios, especialmente las casas de bolsa, fueron sustituyendo a la banca estatal en la función de captación y canalización del ahorro. De este desarrollo emergerían los agentes que más adelante serían los beneficiarios de la privatización, así como los capitales que la hicieron posible. 
Sin embargo, las consecuencias más importantes que acarreó la expropiación fueron la pérdida del capital humano con experiencia en la actividad bancaria y el rezago tecnológico frente a competidores internacionales. Sumida en una lógica similar a la del sector público, la estructura de incentivos se sesgó hacia objetivos distintos al de la eficiencia y la competitividad: el personal que tenía capacidad y experiencia abandonó la actividad bancaria, estimulado por el rezago de los sueldos frente a los que ofrecían las áreas privadas y por las prácticas discrecionales en la asignación de los puestos directivos. A este hecho se agregó la incapacidad del sistema para renovar esa gama de habilidades con los empleados disponibles, pues la escasez de crédito hacia el sector privado impidió que fueran adquiriendo, a lo largo del quehacer laboral, las destrezas necesarias para la administración de riesgos y para la selección de préstamos. Éstos eran escasos y, frecuentemente, otorgados de acuerdo con órdenes que emanaban de las esferas del poder político. La oportunidad de rehabilitar la experiencia y los conocimientos estuvo cerrada porque las instituciones simplemente se alejaron de las tareas que son inherentes al quehacer bancario.

Por otro lado, mientras el mundo asistía a una verdadera revolución tecnológica en el campo de la prestación de servicios financieros, la banca estatal -exonerada de la competencia- no encontró los alicientes para avanzar en el procesamiento informático de datos y en la comunicación a distancia, que ya empezaban a marcar el desempeño competitivo en los mercados internacionales.

A este retraso se sumó el descuido de nuevos mercados, especialmente el de los productos derivados, que más adelante tendrían un crecimiento explosivo. Al retrasar la atención de estos nuevos instrumentos, se perdió un tiempo que hubiera derivado en actitudes más prudentes, cuando la banca privatizada se aventuró, sin el conocimiento suficiente, en la exploración de esos mercados, cuyo manejo era significativamente más complejo que los tradicionales.

En el corto plazo, la banca estatizada nunca puso en peligro el sistema de pagos, ni abrió la posibilidad de una corrida bancaria, porque simplemente no cumplió con su función de intermediación. Sus consecuencias fueron de índole más estructural y, por ello, de más largo plazo: el deterioro de la cultura y de la experiencia bancarias y un rezago modernizador, cuando las 
tendencias hacia la globalización hacían imposible mantenerse al margen de los cambios y la competencia mundiales.

\section{La desregulación financiera: la semilla microeconómica de la crisis}

A medida que las autoridades avanzaron en el saneamiento de las finanzas públicas, se distendieron las ataduras que ligaban el quehacer bancario mexicano a los requerimientos del sector público. Fue entonces el momento de emprender una necesaria desregulación financiera, tendente a adecuar las reglas de operación a esquemas más competitivos, no sólo para el sector sino también para la economía en su conjunto. Las medidas más importantes que apuntaron hacia esta dirección fueron el desmantelamiento de los cajones selectivos de crédito, la desaparición de los encajes legales y la liberación de las tasas de interés.

\subsection{El desmantelamiento de la canalización obligatoria de crédi- to}

En 1989 se eliminaron los cajones de créditos mediante los cuales las autoridades obligaban, desde 1941, a los bancos a canalizar recursos hacia sectores prioritarios. Entre éstos se encontraba el Gobierno, que debía financiar un déficit público creciente, en ausencia de un mercado de títulos de deuda. La aparición de los Cetes en 1978 vino a desbrozar el camino y a apuntalar las operaciones de mercado abierto como mecanismo privilegiado de financiamiento de la deuda interna. A medida que este mecanismo se desarrolló, los cajones pasaron a segundo término y adquirieron un carácter complementario de los recursos provenientes de la venta de obligaciones públicas. El saneamiento de las cuentas estatales acabó por hacerlos totalmente prescindibles: para 1993, la deuda interna gubernamental estaba íntegramente documentada en valores gubernamentales, mientras que cinco años antes sólo cubrían 40 por ciento de esos requerimientos; el resto lo aportaba el Banco de México (40 por ciento) y el sistema bancario (20 por ciento) (Ortiz, 1994:49).

La consecuencia inmediata de esta transformación fue que los bancos quedaron en libertad de canalizar el crédito hacia las actividades y empresas que ellos eligieran, sin más restricción que la disponibilidad de recursos. Ésta dependía crucialmente de dos factores: tasas de interés atractivas para estimular la capta- 
ción y la eliminación de los limitantes impuestos por los encajes legales.

\subsection{La liberación de las tasas de interés}

En el mismo año en que fueron eliminados los cajones crediticios, las autoridades permitieron que los bancos determinaran las tasas de interés de sus actividades activas y pasivas, así como los plazos asociados a ellas.

La existencia de topes máximos, en presencia de fuertes presiones inflacionarias, había derivado en una menor captación bancaria, detrás de la cual se ocultaba la canalización de recursos hacia instrumentos denominados en dólares (1976, 1979-1982) o hacia intermediarios paralelos, capaces de ofrecer mejores condiciones a los depositantes e inversionistas, como sucedió tras la expropiación de los bancos. Para que estuvieran en posibilidades de competir por la captación y por los préstamos, las tasas de interés fueron liberadas. La medida también iba dirigida hacia la reducción de los márgenes de intermediación y a fomentar los costos de captación.

El resultado fue un aumento del ahorro financiero y de la captación bancaria, que sirvieron de base para la futura expansión del crédito, que desembocaría en la crisis bancaria de 1994.

\subsection{La eliminación del encaje legal}

Hasta su eliminación, la política de encaje legal tuvo el propósito de controlar la oferta monetaria por medio de regulaciones a la expansión del crédito interno. Los bancos estaban obligados a canalizar una parte de la captación hacia valores gubernamentales y a mantener tenencias en efectivo en el banco central. La ausencia de operaciones de mercado abierto hasta 1978, habían convertido al encaje legal, junto con el control directo de las tasas de interés, en el principal expediente con que contaba la política monetaria y crediticia. Pero también operaba como un mecanismo de protección del ahorrador, pues representaba una reserva obligada para hacer frente a las obligaciones que los bancos mantenían con los depositantes.

El encaje legal fue eliminado y sustituido en 1989 por un coeficiente de liquidez equivalente a 30 por ciento de la captación, el cual desaparecería dos años después. Con tales medidas, las autoridades se desprendían de sus principales instrumentos 
de política monetaria, y confinaban el control crediticio a las modificaciones en la base monetaria asociadas a la compra y la venta de títulos de deuda pública. Los bancos tenían ya la libertad para expandir el crédito, sin otro freno que el que imponía la prudencia o la falta generalizada de liquidez, que, por lo demás, resultaba incompatible con una economía que aspiraba al crecimiento.

De hecho, la liberación de las tasas de interés y las modificaciones en los encajes legales se encuadraban en el marco más general de política económica. Como se ha expuesto, la estrategia contra la inflación demandó que los déficit en cuenta corriente fueran financiados por los excedentes en los flujos de capital. $\mathrm{Al}$ cambiar a un régimen de política monetaria activa, en el que las tasas de interés están determinadas por el mercado y el comportamiento de base monetaria obedece a metas preestablecidas, el Gobierno apostaba a que la esterilización de las entradas de capital foráneo redujera la expansión del crédito interno. Si éste se expandió, en lugar de restringirse, esa apuesta fracasó por fallas en la política de esterilización, o porque ésta se volvió incongruente con la política cambiaria, obsesión irrenunciable de la administración salinista.

\section{La privatización bancaria}

En mayo de 1990, el Ejecutivo Federal envió al Constituyente la iniciativa para modificar el Artículo 28 constitucional, que otorgaba al Estado el monopolio en la prestación de los servicios bancarios. La finalidad era preparar el terreno jurídico para la privatización de la banca múltiple, que sería iniciada el año siguiente y culminada en 1992.

La venta de las 18 instituciones de crédito a particulares fue un proceso que acarreó al menos tres consecuencias, cuyos efectos se harían sentir de forma contundente en la crisis financiera de 1994. En primer lugar, fueron asignadas de forma privilegiada a personas o grupos con escasa o nula experiencia y conocimiento del negocio bancario. En su gran mayoría, los beneficiarios provenían de las casas de bolsa, que habían cobrado un auge inusitado durante el periodo de la banca estatizada. En este sentido, el Gobierno perdió la oportunidad de restituir el capital humano que se había dilapidado en ese lapso.

La preferencia hacia este tipo de agentes económicos había sido legalmente diseñada por modificaciones legales que precedieron a la privatización. El paquete financiero enviado al Con- 
greso de la Unión en 1989 reconoció la figura de agrupaciones financieras no bancarias; más tarde, la Ley de Instituciones de Crédito, que regiría la operación de la banca mixta, hizo posible que los bancos pudieran formar parte de esos conglomerados. Pero fue la Ley para Regular las Agrupaciones Financieras, también de 1990, la que perfiló a las casas de bolsa como las beneficiarias más probables del proceso de venta: las modalidades que esas asociaciones podían asumir variaban en función de que fueran encabezadas por una sociedad controladora, por un banco o por una casa de bolsa. En el primer caso, la sociedad controladora podía estar conformada por una casa de bolsa y por un banco, mientras que en los otros dos tal asociación era imposible. La tendencia hacia la centralización y hacia la fusión de instancias financieras, a la que ha obligado la competencia internacional, prácticamente representaba un acto premonitorio de que en México tendrían la misma suerte. Privilegiar jurídicamente a las casas de bolsa como sus cabezas de grupo representaba, en los hechos, cerrar el embudo que conducía a la propiedad bancaria.

Las acciones legales para reglamentar la integración del capital hicieron otro tanto a favor de las casas de bolsa. Las declaraciones expresas de las autoridades hacendarias acerca de someter el proceso de privatización a una "democratización" del capital, cobraron vida en la legislación al acotar la tenencia accionaria a 5 por ciento para personas físicas y morales, o a 10 por ciento, si se contaba con la anuencia oficial. Sin embargo, esos límites no actuaban para el Gobierno, el Fobaproa (Fondo Bancario de Protección al Ahorro), los inversionistas institucionales y las agrupaciones financieras, en las que las casas de bolsa ocupaban un lugar destacado como cabezas de grupo. En junio de 1992, un nuevo cambio legal posibilitaría que las agrupaciones financieras pudieran endeudarse con el propósito de capitalizar a sus sociedades o de integrar nuevas instituciones financieras a su grupo: se abría así la posibilidad de que los nuevos propietarios liquidaran con otros pasivos los adeudos que eventualmente pudieran emerger de la compra bancaria. De esta forma, la capacidad de recapitalizar a los bancos en caso de quebrantos se reducía sustancialmente.

En segundo término, el proceso de privatización bancaria fue guiado de forma exclusiva por un criterio mercantil y recaudatorio. El mecanismo de subasta privilegió el precio como norma de asignación. En ningún caso ganó una postura que fuera rebasada en este rubro. Con ello las autoridades, arrastradas por 
el éxito de la convocatoria, olvidaron el carácter estratégico de la banca en la economía nacional. Más importante que la cotización era la capacidad para fortalecer las instituciones de crédito, y por ello, para presentar proyectos de desarrollo de mediano y largo plazos, que incluyeran programas de capitalización, de penetración de mercado y de asignación de recursos hacia los sectores productivos, así como de adaptación a las nuevas circunstancias que había configurado un mundo más competitivo. Los nuevos banqueros creyeron que esas circunstancias eran similares a las que habían prevalecido mientras la economía se mantuvo cerra$\mathrm{da}$, y por eso previeron un negocio altamente rentable $\mathrm{y}$, al mismo tiempo, seguro. Al fincar la venta en el precio mayor $-\mathrm{y}$ a todas luces excesivo-, el Gobierno no sólo confirmó sus ilusiones, sino que además actuó de la misma forma como muy poco tiempo después lo harían los beneficiarios: considerando a la banca un negocio como cualquier otro.

Por último, el alto precio al que fueron cedidos los bancos (3.4 veces el valor en libros) trajo consigo dos consecuencias muy importantes para el deterioro que seguiría el sistema: por un lado, representó un aliciente para la expansión indiscriminada del crédito, que respondía a un afán por recuperar las grandes inversiones involucradas; y por el otro, dejó a sus propietarios sin recursos para la capitalización. Los dos elementos tejieron un círculo vicioso entre la necesidad de contar con mayores recursos para las provisiones y el crecimiento de préstamos cada vez más riesgosos, que sólo acabaría por romperse con las crisis bancarias y de los deudores.

El círculo perverso fue a su vez nutrido por las barreras que se levantaron contra la inversión extranjera, en un afán poco realista de conservar el control bancario en manos de mexicanos. Las disposiciones legales posibilitaban la tenencia accionaria de extranjeros, pero sin derechos corporativos. Con ello se cerraba la posibilidad de que este tipo de inversionistas aportaran un capital y una experiencia que hubieran sido decisivos para un mejor desempeño del sistema. La fuerza de los hechos llevaría a las autoridades a reconocer este error con las modificaciones legales de 1995 y las propuestas de 1998, que ahora debe discutir el Legislativo. Sin embargo, la tardanza acarreó ominosas consecuencias. 


\section{Las fallas en la regulación y en la supervisión}

La liberación de las tasas de interés y la eliminación de los encajes legales constituyen una orientación que tiende a afianzarse en los sistemas financieros mundiales. Su finalidad es hacer de ellos instrumentos más competitivos. Sin embargo, la especificidad del sistema bancario impide que éste asuma una liberación total que ponga en riesgo a los ahorradores (riesgo moral) y al sistema de pagos (riesgo sistémico). Por esta razón, aquellos expedientes deben ser sustituidos por una regulación prudencial y por una efectiva supervisión de las autoridades monetarias y crediticias, que conjuren, o al menos aminoren, esos peligros. Evitar que los bancos incurran en préstamos morosos o irrecuperables debe ser la principal misión de la regulación y de la supervisión.

Si atendemos a los datos de expansión del crédito y a los del comportamiento de la cartera vencida que se registra a partir de la liberación financiera y de la privatización bancaria de 19911992, es claro que la causa microeconómica más importante de la crisis bancaria de 1994 residió en las deficiencias en los rubros de la regulación y la supervisión. Fueron ellas las que abrieron la puerta a la vulnerabilidad del sistema bancario ante los embates del entorno macroeconómico.

De 1989 a 1993, el crédito expedido por la banca central aumentó en 130 por ciento, en términos reales; para 1994, el incremento ya era de 200 por ciento. La expansión del crédito, entonces, comienza con el proceso de liberación financiera iniciado en 1989, cuando la banca todavía era responsabilidad estatal; pero la tendencia continúa cuando ésta pasa a manos privadas. Lo mismo sucede con la cartera vencida: el índice de morosidad salta de 1.43 por ciento en 1989 a más de 8 por ciento en 1994.

Estos indicadores muestran claramente las fallas regulatorias y supervisoras de la autoridad: el porcentaje aceptado por las normas internacionales para la morosidad es de 3.5, que ya había sido rebasado en 1992, cuando el proceso de venta había culminado. Pero la autoridad supervisora, en lugar de frenar esta expansión, permitió que el crédito siguiera expandiéndose, y la morosidad, elevándose.

El fenómeno de las carteras vencidas se viene gestando con anterioridad a la crisis de 1994. Antes de proseguir con las causas microeconómicas que animaron este comportamiento, volvamos a las de naturaleza macro. 
La entrada de capitales foráneos originada por los déficit en cuenta corriente de la balanza de pagos, suscitó una burbuja especulativa en torno a ciertos activos y bienes de consumo (bienes raíces), misma que activó una intensa alza de sus precios. Para obtener ganancias especulativas de esos movimientos, los agentes económicos utilizaron los recursos provenientes del exterior para adquirirlos. El mecanismo de transmisión fueron los préstamos otorgados por el aparato bancario. Es por esta razón que los créditos al consumo y, en especial, a la vivienda, superaron con mucho la tasa de crecimiento general del crédito. Cuando la economía entró en una recesión temporal en 1993, por el afán del Gobierno de reducir la inflación a un dígito, las empresas y los consumidores se encontraron imposibilitados de responder a sus adeudos, pero la burbuja especulativa no cedió. Este fue el antecedente más inmediato de lo que sería la explosión de las carteras vencidas en 1995, cuando esa burbuja especulativa se rompió. Entonces los precios relativos de aquellos activos y bienes de consumo descendieron, y los bancos encontraron una dificultad estructural para su saneamiento: las garantías que respaldaban los créditos fueron insuficientes para cubrirlos.

Pero también -y regresando a las causas micro- los bancos respondieron no sólo con falta de prudencia, sino también con toda la impericia que había germinado en el proceso de privatización. A medida que la cartera vencida crecía, se vieron en necesidad de aumentar -aunque insuficientemente, por su escasa capitalización- las reservas para provisiones. Las presiones sobre las utilidades que tal medida acarreaba, los impulsó a aumentar sus márgenes de intermediación, y con ello, a encarecer el servicio de los adeudos. El resultado fue un proceso de "selección adversa": los buenos deudores adelantaron sus pagos, propiciando que la cartera reflejara un perfil más cargado hacia la morosidad, mientras el flujo de ingresos disminuía. Esto presionaría de nuevo las ganancias, y el ciclo se repetiría.

La libertad de los bancos para elevar indiscriminadamente los márgenes de intermediación revela una enorme laguna del marco regulatorio. Antes del proceso de liberación financiera, el Estado controlaba tanto las tasas de interés activas como las pasivas, y de esta manera, esos márgenes. Cuando se liberan, la autoridad pierde el control de las tasas activas y, así, el de este determinante de la utilidad bancaria. La creencia ciega en la competencia dejó este espacio a cargo de las fuerzas del mercado, sin tomar en cuenta que el sistema bancario es una actividad alta- 
mente concentrada, y por ello, que responde a una estructura oligopólica, en la que son los precios, y no las utilidades, los que reaccionan ante aumentos en los costos.

A esta insuficiencia, el marco regulatorio y la propia supervisión agregaban otras:

a) La falta de suficientes requisitos para acceder al oficio de banquero y para el ejercicio profesional de esa actividad por ciertos ejecutivos.

b) La carencia de normas prudenciales para la asignación de créditos, en especial aquellas que evitan su concentración en personas y actividades y los créditos vinculados.

La tendencia a la concentración del crédito al consumo y a la vivienda fue una de las causas importantes que propiciaron la alta vulnerabilidad de los bancos ante el entorno económico, en la medida en que ambos rubros son los primeros que responden a las bajas del ciclo económico. Así, mientras en 1988 la vivienda absorbía 7 por ciento del crédito total, en 1993 y 1994 esa proporción había alcanzado 13 y 16 por ciento, respectivamente.

Los créditos vinculados eran objetos de restricciones en la legislación, pero permitidos, al final de cuentas. Los casos de Banca Unión y de Banpaís demuestran, sin embargo, que esta permisividad, aunada a la poca capacidad de supervisión, pueden provocar quebranto en las instituciones.

c) Normas débiles para medir, dar seguimiento y responder al comportamiento del riesgo involucrado en los préstamos.

Al liberar la actividad financiera, las autoridades se limitaron a establecer reglas para que los bancos pudieran evaluar la calidad de sus carteras. Con esta decisión, la evaluación quedó en manos de las instituciones de crédito, sin que la autoridad pudiera supervisar el apego a las reglas oficiales. Una de las formas más socorridas para evitar que los balances reflejaran el creciente riesgo fue el refinanciamiento de créditos vencidos: con este mecanismo podía ocultarse la verdadera magnitud de la cartera vencida, bajo la forma de nuevos préstamos vigentes, y así, evitar la intervención de los supervisores, que resultaron incapaces de detectar a tiempo el peligro que se venía gestando.

d) Operación de normas y criterios de contabilidad deficientes, que no permitieron transparentar los índices de morosidad. 
Las normas de contabilidad que regían los estados financieros de los bancos estaban diseñadas para considerar como vencido solamente el monto del principal y los intereses no pagados, y no -como es costumbre en el escenario internacional- la cantidad insoluta, después de que no se han cubierto un número determinado de mensualidades. A pesar de ser altos los índices de cartera vencida, la dimensión de este problema era mucho mayor y apareció más pronto de que lo que manifiestan los indicadores.

En 1996, la autoridad obligó a los bancos a adoptar las normas de contabilidad internacionales, lo que se refleja -por lo menos parcialmente- en el salto que en ese año y el siguiente experimentó la proporción de cartera vencida sobre la total.

e) A pesar de que era pública y notoria la facilidad con la que se otorgaban los préstamos, sobre todo los de consumo, las autoridades supervisoras decidieron no hacer nada para someter a criterios más estrictos este suministro.

La sustitución de los encajes legales por la regulación de prudencia que acompañó al proceso de liberación financiera tuvo, entre otros propósitos, el control selectivo del crédito: con el encaje legal se puede reducir el crédito de todo el sistema, sin discriminar casos y rubros particulares; con la regulación prudencial se persigue evitar este tipo de prácticas, sin que la economía incurra en una falta de liquidez generalizada.

Sin embargo, para que el relajamiento de los controles y la regulación que intenta inocular sentido de prudencia en los banqueros no deriven en quebrantos de las instituciones, es preciso una supervisión efectiva del ritmo al que se expanden los créditos y de los riesgos asociados. Si éstos pudieron ser ocultados por la falta de normas apropiadas, no sucedió lo mismo con la forma como se expedían los créditos al consumo: las tarjetas de crédito y los préstamos para la adquisición de automóviles eran emitidos con requisitos que, en el límite, se reducían al llenado de formularios y a la comprobación de la identidad, sin importar el historial de crédito o la solvencia económica del prestatario. Con esta actitud los bancos habían excluido el riesgo como criterio de asignación del crédito, y la autoridad la solapaba.

f) La capacidad de intervención de la autoridad supervisora era limitada. 
Existe consenso en que los supervisores son siempre rebasados por las operaciones bancarias, sobre todo cuando se está en presencia de un auge crediticio. Dos son las razones principales: por un lado, entre los bancos y la autoridad existe un problema de información asimétrica, a favor de los primeros; por el otro, cuando el crédito se expande a los ritmos a los que lo hizo en México, la asimetría se ensancha, mientras el personal y la capacidad de la instancia supervisora resultan insuficientes para detectar riesgos y frenar su crecimiento. Aunque insuficiente, la mejor salida a este problema la suministra la facultad de la autoridad para auditar procedimientos internos de control y para intervenir a tiempo, en caso de detectar peligros que arriesguen la salud financiera de los bancos. Tales facultades estaban limitadas tanto por la reglamentación como por la dependencia de la Comisión Nacional Bancaria (CNB) de la Secretaria de Hacienda.

g) Al conservar el seguro bancario universal, el proceso de liberación financiera fue incompleto y torpe, porque impidió que las fallas en la regulación prudencial y en la supervisión fueran atemperadas por la disciplina del mercado y, mediante ésta, por una mejor administración de riesgos.

El propósito principal de toda liberación financiera es imprimir un mayor grado de competitividad al sistema bancario. Pero en el caso de México, la lucha por una mayor participación en la captación y en el mercado de préstamos operó por medio de un mecanismo que excluyó la dualidad precio-riesgo, que es característica esencial de la lid en campo bancario. Y en este mecanismo la preservación del carácter universal del seguro bancario jugó un papel decisivo.

En primer lugar, porque los bancos pueden arriesgarse a financiar proyectos con la sola atención de la rentabilidad del mismo, sin contar el riesgo: si la inversión resulta exitosa, los bancos obtienen las ganancias correspondientes; en cambio, si el proyecto fracasa, las consecuencias son sufragadas por los contribuyentes por medio del erario público. Esto alienta la expansión sin freno del crédito y arrastra al sistema a situaciones recurrentemente peligrosas.

En segundo término, la existencia del seguro universal impide una adecuada administración de riesgos: si éste no existiera, el mecanismo del mercado obliga a que los bancos paguen tasas de interés mayores a medida que aumenta el riesgo de su cartera, si quieren atraer depositantes; para poder so- 
portarlas deben exigir tasas activas más altas a los prestatarios, que preferirán a otras instituciones en donde el costo del dinero sea más bajo. Los dos mecanismos conducen a una mejor administración de los riesgos: la única forma de conservar su participación en el mercado de préstamos es ofrecer tasas activas atractivas, que sólo pueden ser resultado de tasas pasivas menores, y por ello, de una situación financiera menos riesgosa. Para lograrla es preciso cuidar la expansión del crédito y restringir los requisitos para su asignación. Con el seguro universal, los bancos pueden ofrecer tasas de interés a sus depositantes con independencia del riesgo implícito en su cartera, pues aquél les asegura que sus ahorros están plenamente garantizados.

La lógica anterior no debe conducir a eliminar el seguro bancario por completo, porque para que el mecanismo opere es preciso que los ahorradores cuenten con información suficiente sobre la situación financiera de las instituciones bancarias, y ésta sólo está al alcance de los grandes ahorradores, que son los que nutren el grueso del ahorro financiero. En el caso de los pequeños, la información es asimétrica; por ello deben permanecer protegidos. Éste es el espíritu que anima las reformas legales propuestas al Congreso de la Unión; pero, otra vez, llegan tarde.

h) La autoridad encargada del seguro pospuso la intervención oportuna de los bancos, porque incurrió en el mismo patrón de conducta que ellos, tras agotarse sus recursos después de las primeras intervenciones bancarias.

A pesar de que la expansión de la cartera vencida fue evidente, el Fobaproa pospuso varias veces la intervención de bancos que ya anunciaban sus problemas, porque simplemente carecía de los recursos financieros para hacer efectiva esa operación, pero sobre todo porque no contaba con facultades para imponer mayores cuotas a los bancos, a medida que los riesgos aumentaban.

Cuando sobrevinieron las primeras intervenciones en 1994 -Banca Unión y Banpaís-, los recursos del Fondo prácticamente se agotaron. Las posibilidades de rehabilitarlos, como sucedió una vez que la crisis estalló, dependían de una decisión que rebasaba el ámbito de su competencia: de la voluntad del Ejecutivo. El error estribó en que el Fondo se nutría de cuotas ordinarias y extraordinarias impuestas a los bancos en operación y a los nuevos, en función de la captación, y no del 
volumen de préstamos, ponderados por el riesgo. De esta forma, su lógica de conservación llevó a sus autoridades a posponer la intervención bancaria, antes que a solicitar un cambio en las reglas para su propia capitalización.

\section{La política económica después de la crisis}

La crisis estalló en 1994 bajo la forma de una macrodevaluación, que respondía a la imposibilidad de mantener los niveles deseados de tipo de cambio y a una profunda caída del nivel de reservas internacionales. La primera tarea que el nuevo Gobierno debía desplegar era la estabilización del tipo de cambio y la restitución de esos activos internacionales. Ello implicaba un profundo ajuste de la demanda, cuyos efectos serían devastadores para el sistema bancario.

\section{El ajuste macroeconómico}

La crisis se manifestaba principalmente como un problema de balanza de pagos, ocasionado por el exceso del gasto privado, en virtud de que las finanzas públicas habían mostrado un relativo equilibrio durante los años anteriores. Pero también el repunte de la inflación, provocado por la devaluación, representaba un fenómeno que debía enfrentarse si se aspiraba volver a las condiciones de estabilidad.

Las medidas principales fueron: el alza en las tasas de interés, mediante una política monetaria restrictiva que redujo el nivel de la economía; el incremento de tasas impositivas que gravaban el gasto (Impuesto al Valor Agregado); y la reducción del gasto público, en términos reales. Con tales acciones se buscó reducir el gasto en consumo y en la inversión para aumentar los niveles de ahorro privado, por un lado; y por el otro, convertir en superávit, déficit público: es decir, aumentar el ahorro interno de tal forma que se reflejara en una disminución del externo, representado por el saldo negativo en la cuenta corriente de la balanza de pagos.

Estas medidas propiciaron una enorme caída en la demanda agregada, que se tradujo en una disminución del PIB de más de 6 por ciento, la cual no se registraba desde la crisis de 1929. De esta forma, numerosas personas perdieron su empleo; las empresas vieron cómo sus ventas disminuían, mientras el ingreso per- 
sonal disponible real caía estripitosamente por el aumento en los impuestos y en los precios y, en muchos casos, por la disminución de los ingresos nominales.

Por otro lado, la corrección en el exceso de gasto privado y la necesidad de evitar más la fuga de capitales, ameritaron un alza tan intensa en los tipos de interés, que las tasas pasivas pasaron de 18 a 49 por ciento de 1994 a 1995. Con ello, el servicio de las deudas que se mantenían con los bancos alcanzó niveles insostenibles. Los deudores se vieron entonces imposibilitados para continuar cumpliendo con sus obligaciones: por un lado debían pagar más; por el otro, sus ingresos habían disminuido significativamente. Esos dos elementos conformaron la tenaza que precipitó la crisis financiera de los bancos como una crisis de deudores.

\section{El rescate bancario}

La crisis bancaria se había manifestado como una crisis de carteras vencidas, sin posibilidad de restituir el servicio bancario en el corto plazo, en virtud de la precariedad de las condiciones de los acreedores, activada por los efectos de la política económica. Las autoridades emprendieron el rescate bancario mediante dos líneas estratégicas. La primera se orientó directamente a las instituciones de crédito; la segunda, a los deudores. Sin embargo, fue el apoyo al sistema bancario la estrategia fundamental, en la medida en que los recursos destinados a este fin llegaron a representar 65 mil millones de dólares, mientras que los que se canalizaron con los programas de apoyo a los acreedores representaron 10 por ciento de esa cifra.

La estrategia orientada directamente al apoyo bancario fue desplegada mediante tres tipos de acciones:

a) El otorgamiento de créditos blandos, mediante el Programa de Capitalización Temporal.

b) La adquisición de activos dañados o la asunción de pérdidas, según el banco presentara problemas de liquidez o de insolvencia. En el primer caso, se procedió a comprar cartera vencida mediante pagarés liquidables a diez años y generadores de intereses capitalizables a tasas equivalentes a la de Cetes a 90 días, y a cambio de que los bancos aportaran un peso de capital por dos de cartera comprada; en el segundo, se aportó 
la diferencia entre pasivos y activos, con el objeto de sanear a las instituciones y proceder a su venta o liquidación.

c) Fortalecimiento directo de la estructura de capital, mediante aportaciones directas a cambio de acciones o de obligaciones subordinadas emitidas por las instituciones crediticias.

De las tres, las segunda fue la más privilegiada. Pero también la más costosa: cuando los bancos experimentaban problemas de insolvencia, la única alternativa era su liquidación o su venta; pero para que ésta fuera factible, el Gobierno debía, al menos, dejar su capital (diferencia entre activos y pasivos) en cero, destinando a fondo perdido los recursos canalizados para tal efecto. Era tal el deterioro de estas instituciones, que sin esa intervención la venta era imposible. En este sentido, la capacidad de recuperación de esos recursos era prácticamente nula, o muy reducida, si la venta entrañaba una prima sobre el valor de capital.

Cuando la situación financiera mostró posibilidades de ser restituida, porque los problemas eran esencialmente de liquidez, la segunda línea estratégica se perfiló hacia la compra de cartera vencida. Bajo esta opción, el costo fiscal tenía que ser mayor en virtud de que el valor de adquisición debía ser menor a su valor real, de que generaba intereses y de que el esquema de pérdidas se repartía inequitativamente a favor de los bancos. Las autoridades compraron por ese concepto los derechos de cobro de 27 por ciento de la cartera total. A diciembre de 1997, el valor nominal de la cartera vencida adquirida por el Gobierno era de 168 mil millones de pesos, por los cuales pagó 134 mil millones. De ésta, se espera recuperar sólo 30 por ciento, resultando una pérdida de 94 mil millones, a repartir entre el Gobierno ( 75 por ciento) y los bancos (25 por ciento).

De haberse privilegiado la opción de aportar capital a cambio de acciones y obligaciones subordinadas, el costo fiscal hubiera sido menor: por un lado, el efecto sobre la salud de los bancos hubiera sido más directo, al tiempo que hubiera posibilitado una mejor rehabilitación; por el otro, esta mejoría, tarde que temprano, habría redundado en una revaloración de las acciones y las obligaciones. Así, la recuperación de los recursos fiscales destinados al rescate habría sido mayor, y el costo fiscal, menor. 


\section{Conclusiones}

La crisis financiera fue detonada por factores de naturaleza macroeconómica, asociados a la crisis de 1994 y a la política de estabilización que le siguió. Ambas condujeron a alzas impresionantes en las tasas de interés y a caídas drásticas del nivel de actividad, del ingreso personal disponible y del empleo, que deterioraron la calidad de los activos bancarios, depreciaron el valor de las garantías vinculadas a los préstamos y expandieron las carteras vencidas.

La crisis se gestó con el abuso de la política cambiaria, que sirvió de eje a la estrategia contra la inflación iniciada con los Pactos. Tal abuso condujo a una expansión del déficit en la cuenta corriente de la balanza de pagos, que arrojó una proporción del PIB similar a la que precedió a la crisis de 1982. Su financiamiento reposó en los flujos de capitales externos, que sirvieron para financiar la inversión y el consumo, y por esta vía, para generar un auge crediticio, que operó como el antecedente macroeconómico de la crisis bancaria.

Por otro lado, la devaluación afectó a los bancos que, incentivados por la aparente firmeza del tipo de cambio, suministraron créditos en moneda extranjera. Así mismo, la resistencia de las autoridades a modificar a tiempo la política cambiaria desembocó en una devaluación obligada, ya no por la necesidad de mantener el poder de compra de la paridad, sino por la insolvencia en materia de reservas internacionales. De esta forma, se hizo ineludible recurrir a una política económica restrictiva, cuyos efectos sobre las tasas de interés, el ingreso personal y el nivel de actividad, fueron devastadores para la salud de las instituciones financieras.

La revisión de las causas macro y microeconómicas revela que tanto la crisis de la economía mexicana iniciada en 1994, como la financiera que le siguió, fueron producto de errores en el manejo de la política económica y en la financiera. En la primera, la principal responsabilidad reposó en la obstinación del Gobierno de proseguir combatiendo la inflación con un tipo de cambio sobrevaluado, a pesar del peligro que repesentaban los desequilibrios externos y la fragilidad de los flujos externos de capital. A ella se aunó la impericia mostrada en diciembre de 1994 en el manejo del tipo de cambio, misma que posibilitó que en unos cuantos días las reservas internacionales cayeran drásticamente. 
En el ámbito financiero, los errores fueron la forma como se liberó el sistema financiero, el proceso de privatización y, sobre todo, las fallas en el marco regulatorio y en ejercicio de la supervisión, que dieron pie a una expansión desmedida del crédito y de las carteras vencidas, en un marco en que el alto precio pagado por los bancos había dejado a sus accionistas sin márgenes suficientemente amplios para su capitalización. Cuando los peores efectos de ambos procesos -el macro y el micro- desembocaron en un mismo punto, la crisis financiera no se hizo esperar. 
Cuadro 1

Productividad de la mano de obra en la industria manufacturera

\begin{tabular}{|l|l|l|c|c|}
\hline \multirow{2}{*}{ Año } & \multirow{2}{*}{ México } & \multirow{2}{*}{$\begin{array}{l}\text { Estados } \\
\text { Unidos }\end{array}$} & \multicolumn{2}{|c|}{ Variación porcentual } \\
\cline { 4 - 5 } & & México & E.U. \\
\hline 1985 & 106.7 & 122.1 & & \\
1986 & 104.3 & 126.0 & -2.2 & 3.2 \\
1987 & 107.1 & 130.1 & 2.7 & 3.3 \\
1988 & 110.9 & 136.0 & 3.5 & 4.5 \\
1989 & 118.7 & 137.5 & 7.0 & 1.1 \\
1990 & 126.2 & 143.4 & 6.3 & 4.3 \\
1991 & 133.4 & 145.6 & 5.7 & 1.5 \\
\hline
\end{tabular}

FUENTE: Elaboración propia con datos del INEGI, Indicadores de competitividad de la economía mexicana, Aguascalientes, 1992.

\section{Cuadro 2}

Crecimiento del PIB, inflación y saldo en la cuenta corriente de la balanza de pagos

\begin{tabular}{|c|c|c|c|}
\hline & $\begin{array}{c}\text { PIB. } \\
\text { Tasa de } \\
\text { crecimiento }\end{array}$ & Inflación & $\begin{array}{c}\text { Saldo en } \\
\text { cuenta } \\
\text { corriente }\end{array}$ \\
\hline Año & $\%$ & $\%$ & \% del PIB \\
\hline 1978 & 9.0 & 16.2 & $-2-6$ \\
1979 & 9.7 & 20.0 & -3.6 \\
1980 & 9.2 & 29.8 & -5.4 \\
1981 & 8.8 & 28.7 & 7.0 \\
\hline 1986 & -3.2 & 105.8 & -1.6 \\
1987 & 1.7 & 159.2 & 4.8 \\
1988 & 1.3 & 51.7 & -1.4 \\
1989 & 3.5 & 19.7 & -3.0 \\
1990 & 4.4 & 29.9 & -3.2 \\
1991 & 3.6 & 18.8 & -5.2 \\
1992 & 2.8 & 11.9 & -7.5 \\
1993 & 0.7 & 8.0 & 6.6 \\
1994 & 4.4 & 7.0 & -6.6 \\
1995 & -6.2 & 52.0 & -0.7 \\
\hline
\end{tabular}

FuENTE: Banco de México, Indicadores económicos; e INEGI, Sistema de cuentas nacionales. 
Cuadro 3

Tipo de cambio real

(Índice 1977=100)

\begin{tabular}{|c|c|}
\hline Año & $\begin{array}{c}\text { Tipo de } \\
\text { cambio real }\end{array}$ \\
\hline 1987 & 130.9 \\
1988 & 107.6 \\
1989 & 99.6 \\
1990 & 100.2 \\
1991 & 91.3 \\
1992 & 86.0 \\
1993 & 80.8 \\
1994 & 86.0 \\
\hline
\end{tabular}

FUENTE: Elaboración propia con datos del

Banco de México, Indicadores económicos.

\section{Cuadro 4}

Penetración de importaciones en la demanda interna y coeficiente de sustitución de importaciones

\begin{tabular}{|c|c|c|}
\hline Año & $\begin{array}{c}\text { Penetración de } \\
\text { importaciones } \\
\%\end{array}$ & $\begin{array}{c}\text { Coeficiente de } \\
\text { sustitución } \\
\%\end{array}$ \\
\hline 1988 & 13.2 & 11.6 \\
1989 & 13.8 & 12.1 \\
1990 & 14.2 & 12.5 \\
1991 & 13.7 & 12.3 \\
1992 & 14.0 & 12.7 \\
1993 & 13.2 & 11.9 \\
1994 & 14.7 & 13.2 \\
1995 & 18.9 & 15.7 \\
1996 & 20.8 & 17.0 \\
\hline
\end{tabular}

FUENTE: Elaboración propia con información del INEGI, "S.C.N.M. Nueva presentación". 


\section{Cuadro 5}

Financiamiento del déficit en cuenta corriente y composición de la inversión extranjera

\begin{tabular}{|c|c|c|}
\hline \multicolumn{3}{|c|}{ Saldo corriente como proporción de: } \\
\hline \multirow{3}{*}{1988} & $\begin{array}{c}\text { Superávit } \\
\text { cuenta de } \\
\text { capital } \\
\%\end{array}$ & $\begin{array}{c}\text { Inversión } \\
\text { extranjera } \\
\text { directa } \\
\text { \% }\end{array}$ \\
\cline { 2 - 3 } 1989 & 204.26 & 82.25 \\
1990 & 183.30 & 183.31 \\
1991 & 51.27 & 282.95 \\
1992 & 91.71 & 312.77 \\
1993 & 72.04 & 556.32 \\
1994 & 201.72 & 533.16 \\
\end{tabular}

Participación en la inversión extranjera de:

\begin{tabular}{|c|c|c|}
\hline & $\begin{array}{c}\text { Directa } \\
\%\end{array}$ & $\begin{array}{c}\text { Cartera } \\
\%\end{array}$ \\
\cline { 2 - 3 } 1988 & 74.25 & 25.75 \\
1989 & 90.04 & 9.96 \\
1990 & 43.86 & 56.14 \\
1991 & 27.20 & 72.80 \\
1992 & 19.58 & 80.42 \\
1993 & 13.18 & 86.82 \\
1994 & 57.28 & 42.72 \\
\hline
\end{tabular}

FUENTE: Elaboración propia con datos del INEGI, Sistema de cuentas nacionales. 


\section{Cuadro 6 \\ Oferta y demanda globales \\ (tasas medias de crecimiento: 1987-1994)}

\begin{tabular}{|lc|}
\hline & $\%$ \\
\hline PIB & 3.0 \\
Importaciones & 24.1 \\
Oferta & 5.4 \\
\hline
\end{tabular}

\begin{tabular}{|lc|}
\hline Demanda & 5.4 \\
Consumo & 4.1 \\
Inversión & 6.0 \\
Exportaciones & 10.6 \\
\hline
\end{tabular}

FuENTE: Elaboración propia con información del Banco de México, Indicadores económicos. 


\section{Cuadro 7}

\section{Captación bancaria como proporción del ahorro financiero}

\begin{tabular}{|c|c|c|c|}
\hline Año & $\begin{array}{c}\text { Ahorro financiero } \\
\text { (millones de } \\
\text { pesos) }\end{array}$ & $\begin{array}{c}\text { Captación } \\
\text { (millones de } \\
\text { pesos) }\end{array}$ & $\begin{array}{c}\text { Captación/ahorro } \\
\text { financiero } \\
\%\end{array}$ \\
\hline 1980 & 1202.4569 & 820 & 68.19 \\
1981 & 1795.3868 & 1148 & 63.94 \\
1982 & 3145.0938 & 2333 & 74.18 \\
1983 & 5417.2461 & 3933 & 72.60 \\
1984 & 9283.554 & 6651 & 71.64 \\
1985 & 14975.3349 & 9303 & 66.09 \\
1986 & 29587.2432 & 16550 & 55.94 \\
1987 & 77251.3077 & 39421 & 51.03 \\
1988 & 120979.874 & 23626 & 19.53 \\
1989 & 184265.334 & 67613 & 36.69 \\
1990 & 271816.657 & 132694 & 48.82 \\
1991 & 355583.514 & 203329 & 57.18 \\
1992 & 427026.322 & 252259 & 59.07 \\
1993 & 544888.005 & 291413 & 53.48 \\
1994 & 676863.41 & 334858 & 49.47 \\
1995 & 820057.059 & 437580 & 53.36 \\
1996 & 1091519.8 & 597181 & 54.71 \\
1997 & 1413267.62 & 776464 & 54.94 \\
\hline
\end{tabular}

FuENTE: Elaboración propia con información del Banco de México, Indicadores económicos.

Cuadro 8

Cartera vencida como proporción de la cartera total

\begin{tabular}{|cc|}
\hline Año & $\%$ \\
\hline 1989 & 1.43 \\
1990 & 2.35 \\
1991 & 3.07 \\
1992 & 4.14 \\
1993 & 5.44 \\
1994 & 8.29 \\
1995 & 12.33 \\
1996 & 11.39 \\
1997 & 14.98 \\
\hline
\end{tabular}

FuENTE: Elaboración propia con datos del Banco de México, Indicadores económicos. 


\section{Cuadro 9 \\ Indicadores sobre la privatización de los bancos}

\begin{tabular}{|c|c|c|c|}
\hline Banco & Comprador & $\begin{array}{l}\text { Valor de venta } \\
\text { (millones de } \\
\text { nuevos pesos) }\end{array}$ & $\begin{array}{l}\text { Número de veces } \\
\text { el valor en libros } \\
\text { y siguientes } \\
\text { mejores posturas }\end{array}$ \\
\hline \multicolumn{4}{|l|}{ Primera etapa } \\
\hline Multibanco Mercantil & $\begin{array}{l}\text { José Madariaga } \\
\text { Lomelí: Probursa }\end{array}$ & 611.2 & $\begin{array}{r}\text { Venta: } 2.66 \\
\text { Siguiente: } 2.47\end{array}$ \\
\hline \multirow[t]{2}{*}{ Banpaís } & $\begin{array}{l}\text { Julio Villarreal y Policarpo } \\
\text { Elizondo; se agregan }\end{array}$ & & \\
\hline & $\begin{array}{l}\text { Ángel Rodríguez y José Rión, } \\
\text { de Mexival }\end{array}$ & 545 & $\begin{array}{r}\text { Venta: } 3.02 \text {; } \\
\text { Siguiente: } 86\end{array}$ \\
\hline Banca Cremi & Manuel Somoza & ND & $\begin{array}{r}\text { Venta: } 2.5 \\
\text { Siguiente: } 2.4\end{array}$ \\
\hline \multicolumn{4}{|l|}{ Segunda etapa } \\
\hline Banca Confía & Jorge Lankenau, de Ábaco & 892.26 & $\begin{array}{r}\text { Venta: } 3.73 \text {; } \\
\text { Siguientes: } \\
3.70 \text { y } 3.10\end{array}$ \\
\hline Banco del Oriente & $\begin{array}{l}\text { Marcelo y Ricardo } \\
\text { Margain Berlanga }\end{array}$ & 223.22 & $\begin{array}{r}\text { Venta: } 4.0 \text {; } \\
\text { Siguientes: } 3.61 \text { y } 3.67\end{array}$ \\
\hline Bancreser & Roberto Alcántara & 425.13 & $\begin{array}{r}\text { Venta: } 2.53 \\
\text { Siguiente: } 2.54\end{array}$ \\
\hline Banamex & $\begin{array}{l}\text { Roberto Hernández y } \\
\text { Alfredo Harp Helú, de Accival }\end{array}$ & 9744.98 & 2.62 y 2.32 \\
\hline \multicolumn{4}{|l|}{ Tercera etapa } \\
\hline Bancomer & $\begin{array}{l}\text { Ricardo Guajardo Touché } \\
\text { y Eugenia Garza Laguera, de }\end{array}$ & 77995 & Venta. 299 \\
\hline $\mathrm{BCH}$ & Carlos Cabal Peniche & 878.36 & $\begin{array}{r}\text { Siguiente: } 2.82 \\
\text { Venta: } 2.67 \\
\text { Siguiente: } 2.65\end{array}$ \\
\hline \multicolumn{4}{|l|}{ Cuarta etapa } \\
\hline Serfín & $\begin{array}{l}\text { Adrián Sada, Gastón Luken } \\
\text { y Guillermo Ballesteros (Obsa) }\end{array}$ & 2827.8 & $\begin{array}{r}\text { Venta: } 2.69 \\
\text { Siguiente: } 2.55\end{array}$ \\
\hline Comermex & $\begin{array}{l}\text { Agustín Legorreta y Guillermo } \\
\text { Sottil, de Inverlat }\end{array}$ & 2076.00 & $\begin{array}{r}\text { Venta: } 3.73 \\
\text { Siguiente: } 3.66\end{array}$ \\
\hline Baco Mexicano Somex & $\begin{array}{l}\text { Carlos Gómez y Gómez, } \\
\text { de Invermexico }\end{array}$ & 1876.5 & $\begin{array}{r}\text { Venta: } 3.3 \\
\text { Siguiente: } 2.9\end{array}$ \\
\hline \multicolumn{4}{|l|}{ Quinta etapa } \\
\hline Atlántico & Alfonso de Garay y Jorge Rojas & 1469.2 & $\begin{array}{r}\text { Venta: } 5.3 \\
\text { Siguiente: } 4.59\end{array}$ \\
\hline Promex & Eduardo Carrillo, de Finamex & 1074.5 & $\begin{array}{r}\text { Venta: } 4.23 \\
\text { Siguiente: } 3.7\end{array}$ \\
\hline Banoro & Rodolfo Esquer & 1137.81 & $\begin{array}{r}\text { Venta: } 3.95 \\
\text { Siguiente: } 3.3\end{array}$ \\
\hline \multicolumn{4}{|l|}{ Sexta etapa } \\
\hline $\begin{array}{l}\text { Banco Mercantil del } \\
\text { Norte }\end{array}$ & Roberto Gonzáles Barrera & 1775.6 & $\begin{array}{r}\text { Venta: } 4.25 \\
\text { Siguiente: } 4.2\end{array}$ \\
\hline Banco Internacional & Antonio del Valle, de Prime & 1486.9 & $\begin{array}{r}\text { Venta: } 2.95 \\
\text { Siguiente: } 2.5\end{array}$ \\
\hline Bancen & $\begin{array}{l}\text { Hugo Villa, de Multiva Grupo } \\
\text { Financiero }\end{array}$ & 869.4 & $\begin{array}{r}\text { Venta: } 4.65 \\
\text { Siguiente: } 4.24\end{array}$ \\
\hline
\end{tabular}

FUENTE: Elaboración propia con datos de Guillermo Ortiz, La reforma financiera y la desincorporación bancaria. 


\section{Cuadro 10}

Ahorro financiero y penetración financiera (porcentajes del PIB)

\begin{tabular}{|c|c|c|}
\hline Años & $\begin{array}{c}\text { Ahorro financiero } \\
\%\end{array}$ & $\begin{array}{c}\text { Penetración financiera } \\
\%\end{array}$ \\
\hline 1970 & 22.9 & 29.5 \\
1971 & 24.2 & 30.6 \\
1972 & 24.5 & 31.2 \\
1973 & 21.9 & 28.5 \\
1974 & 19.5 & 25.7 \\
1975 & 20.7 & 26.7 \\
1976 & 17.5 & 23.0 \\
1977 & 10.7 & 17.2 \\
1978 & 13.1 & 20.0 \\
1979 & 14.0 & 21.1 \\
1980 & 20.3 & 26.9 \\
1981 & 23.2 & 29.3 \\
1982 & 26.9 & 32.1 \\
1983 & 26.1 & 30.3 \\
1984 & 27.0 & 31.5 \\
1985 & 25.3 & 29.7 \\
1986 & 32.3 & 37.2 \\
1987 & 35.1 & 39.9 \\
1988 & 28.5 & 30.8 \\
1989 & 33.7 & 36.3 \\
1990 & 35.7 & 39.6 \\
1991 & 31.9 & 41.1 \\
1992 & 32.7 & 41.9 \\
1993 & 38.3 & 47.6 \\
1994 & 44.3 & 52.2 \\
1995 & 42.6 & 48.9 \\
1996 & 40.3 & 47.1 \\
1997 & 41.4 & 48.7 \\
& & \\
\hline
\end{tabular}

FuENTE: Elaboración propia con información del Banco de México, Indicadores económicos. 


\section{Bibliografía}

Aspe, P. (1993), El camino mexicano de la transformación económica, México, Fondo de Cultura Económica.

Casar, José (1989), Transformación en el patrón de especialización y comercio exterior del sector manufacturero mexicano 1978-1987, México, Nacional Financiera.

Chacholiades, S. (1986), Economía internacional, México, Mac Graw-Hill.

Dornbush, R. y S. Fischer (1985), Macroeconomía, México, Mac Graw-Hill.

Lustig, N. (1995), "México y la crisis del peso: lo previsible y la sorpresa", Comercio Exterior, vol. 45, núm. 5.

Millán, H. (1997), "Penetración de importaciones y dinamismo exportador", Investigación Económica, vol. LVII, num. 221, julio-septiembre.

Ortiz, G. (1994), La reforma financiera y la desincorporación bancaria, México, Fondo de Cultura Económica.

Quijano, J. (1982), México: Estado y banca privada, México, Centro de Investigación y Docencia Económicas.

Ramírez de la O, R. (1996), "La crisis del peso mexicano y la recesión 1994-1995: ¿previsible entonces, evitable en el futuro?”, en R. Roett, La crisis del peso mexicano. Perspectivas internacionales, México, Fondo de Cultura Económica.

Tello, C. (1979), La política económica en México 1970-1976, México, Siglo XxI. 